\title{
SINTOMAS VISUAIS DE DEFICIÊNCIA DE MACRONUTRIENTES E BORO EM MARACUJAZEIRO-DOCE ${ }^{1}$
}

\author{
MARTA SIMONE MENDONÇA FREITAS ${ }^{2}$, PEDRO HENRIQUE MONNERAT ${ }^{3}$, \\ ALMY JUNIOR CORDEIRO DE CARVALHO ${ }^{4}$, MARCOS ANTÔNIO DA SILVA VASCONCELLOS ${ }^{5}$
}

RESUMO - Conduziu-se experimento em casa de vegetação com objetivo de caracterizar sintomas visuais de deficiências de macronutrientes e de $\mathrm{B}$ em folhas e frutos de maracujazeiro-doce cultivados em caixas com areia lavada e irrigados com solução nutritiva. Utilizou-se delineamento experimental em blocos casualizados, com oito tratamentos (solução completa, $-\mathrm{N},-\mathrm{P},-\mathrm{K},-\mathrm{Ca},-\mathrm{Mg},-\mathrm{S}$ e $-\mathrm{B}$ ), com quatro repetições. Os sintomas de deficiência observados, entre 85 e 240 dias após a aplicação dos tratamentos, foram: -N: clorose generalizada e queda prematura das folhas e frutos com cor verde- amarelada e aspecto translúcido; -P: folhas velhas com coloração verde-escura brilhante que, com progressão da deficiência, ficavam mais claras; -K: clorose e posterior necrose na porção basal da nervura central das folhas velhas que progrediam para as bordas e queda das folhas e frutos com enrugamento do epicarpo; -Ca: deformação e necrose nas bordas das folhas novas e frutos com rachaduras no epicarpo e no mesocarpo, além de podridão apical; -Mg: folhas velhas com clorose internerval; $-\mathrm{S}$ : clorose das folhas novas com pequenas manchas mais claras e-B: folhas novas com aspecto coriáceo e ondulação nos bordos e frutos com faixas marrons de cortiça na casca. Termos para indexação: Passiflora alata, nutrientes minerais, folha, fruto.

\section{DEFICIENCY SYMPTOMS OF MACRONUTRIENTES AND BORON IN SWEET PASSION FRUIT PLANT}

\begin{abstract}
The experiment was carried out in a greenhouse aiming to characterize visual symptoms of macronutrients and B deficiency in leaves and fruits of sweet passion fruit plants cultivated in box with sand and irrigated with nutrient solutions. It was used eight treatments in a complete randomized block design, as follow (complete nutrient solution, $-\mathrm{N},-\mathrm{P},-\mathrm{K},-\mathrm{Ca},-\mathrm{Mg},-\mathrm{S}$ and $-\mathrm{B}$ ), with four replicates. Symptoms of deficiency were observed between 85 and 240 days after the application of the treatments, - N: uniform chlorosis and premature fall of leaves and yellowish green color fruits and translucent aspect; - P: old leaves with dark green color and, later, white spots on the surface of the leaves; - K: chlorosis and subsequent necrosis of the basal portion of the central rib of old leaves that progressed to the borders, and fall of the leaves and fruits wrinkling of the epicarp with consequent wilting of the fruit; -Ca: deformation and necrosis of the borders of new leaves and fruits cracks in the epicarp and in the mesocarp and apical rot of the fruits; - Mg: old leaves with internerval chlorosis; - S: chlorosis of new leaves with small colorless spots and; - B: new leaves with coriaceous aspect and undulation in the boards and fruits with brown bands of cork on the peel. Index terms: Passiflora alata, mineral nutrients, leaves, fruit.
\end{abstract}

\footnotetext{
'(Trabalho 096-10). Recebido em: 19-04-2010. Aceito para publicação em: 22-08-2011. Apoio Financeiro: CNPq e FAPERJ. ${ }^{2} \mathrm{Dr}^{\mathrm{a}}$. em Produção Vegetal, Universidade Estadual do Norte Fluminense Darcy Ribeiro, Av. Alberto Lamego, 2000, CEP 28.013-602. E-mail:msimone@uenf.br

${ }^{3}$ Ph.D. em Nutrição Mineral de Plantas, Universidade Estadual do Norte Fluminense Darcy Ribeiro, Av. Alberto Lamego, 2000, CEP 28.013-602. E-mail: monnerat@uenf.br

${ }^{4}$ Dr. em Fruticultura, Universidade Estadual do Norte Fluminense Darcy Ribeiro, Av. Alberto Lamego, 2000, CEP 28.013-602. E-mail: almy@uenf.br

${ }^{5}$ Dr. Em Horticultura, Universidade Federal Rural do Rio de Janeiro. E-mail: masv@ufrrj.br
} 


\section{INTRODUÇÃO}

O diagnóstico visual do estado nutricional das plantas consiste em caracterizar, descrever e/ou fotografar, mais precoce e detalhadamente possível, os sintomas de deficiência ou toxidez na plantaproblema e compará-los com os sintomas-padrão descritos na literatura. Alguns trabalhos utilizando a diagnose visual já foram realizadas com algumas frutíferas, como gravioleiras (BATISTA et al., 2003), umbuzeiro (NEVES et al., 2004), camucamuzeiro (VIÉGAS et al., 2007) e abacaxizeiro (RAMOS et al., 2009). Segundo Malavolta et al. (1997), as funções desempenhadas por determinado nutriente, como constituinte de compostos, independemente da espécie vegetal, razão pela qual os sintomas de carência, em linhas gerais, se assemelham em diferentes espécies de plantas. Entretanto, a deficiência de um nutriente não altera, necessariamente, o mesmo processo metabólico em todas as espécies.

Para a espécie de maracujazeiro-amarelo alguns trabalhos, como o de Fernandes et al. (1991), caracterizam os sintomas de deficiência de macronutrientes, entretanto durante o período de avaliação do experimento, 55 dias após o transplante, só foi possível verificar sintomas de deficiência de $\mathrm{Ne}$ $\mathrm{Mg}$, iniciado aos oito e quinze dias, respectivamente. Martinez e Araújo (2001) não observaram sintomas de deficiência de $\mathrm{K}$ durante o tempo de condução do experimento, assim como os sintomas de deficiência de P, em plantas de 76 dias, mantidas sob omissão de $\mathrm{K}$ e P por 36 dias em solução nutritiva, demonstrando a necessidade de se avaliar por mais tempo, ou seja, até a frutificação, os sintomas de deficiência desses nutrientes.

Para o maracujazeiro-doce, o único trabalho que relata os sintomas de deficiência nutricional é o de Cereda et al. (1991). No referido artigo, as plantas foram colhidas com 70 dias, e os autores obtiveram massa fresca da parte aérea que variou de 28,3 g planta $^{-1}$ no tratamento - Mg a 2,00 g planta $^{-1}$ no tratamento -N, sendo que, no tratamento completo, a massa obtido foi de 13,4 g planta ${ }^{-1}$. Neste trabalho, para a identificação dos sintomas de deficiências, os autores comparam com aqueles descritos para o maracujazeiro-amarelo e concluíram que os sintomas visuais foram semelhantes entre as duas espécies de Passiflora.

Sendo assim, é possível que os sintomas visuais de deficiência de um determinado nutriente não sejam expressos em curto espaço de tempo, demonstrando a necessidade de estudos de longa duração, os quais contemplem toda a fenologia da planta. $\mathrm{O}$ presente trabalho objetivou descrever e caracterizar os sintomas de deficiência dos nutrientes $\mathrm{N}, \mathrm{P}, \mathrm{K}, \mathrm{Ca}$, $\mathrm{Mg}, \mathrm{S}$ e B em folhas e frutos de maracujazeiro-doce.

\section{MATERIAL E MÉTODOS}

O experimento foi realizado em casa de vegetação, no Câmpus da Universidade Estadual do Norte Fluminense Darcy Ribeiro, localizada no Município de Campos dos Goytacazes -RJ (latitude de $21^{\circ} 19^{\prime} 23^{\prime \prime} \mathrm{S}$; longitude de $41^{\circ} 10^{\prime} 40^{\prime \prime} \mathrm{W}$; altitude de $14 \mathrm{~m}$ ) no período de 30-09-2004 a 12-11-2005. Durante a condução do experimento, foram tomadas as temperaturas diárias dentro da casa de vegetação, sendo que as máximas variaram entre $29,7^{\circ} \mathrm{C}$ e $38,7^{\circ} \mathrm{C}$, com média das máximas igual a $35,1^{\circ} \mathrm{C}$, as temperaturas diárias mínimas entre $17,5^{\circ} \mathrm{C}$ e $22,5^{\circ} \mathrm{C}$, com média das mínimas igual a $20,2^{\circ} \mathrm{C}$ e a temperatura média diária variando de $24,5^{\circ} \mathrm{C}$ a $32,5^{\circ} \mathrm{C}$, com média igual a $28,7^{\circ} \mathrm{C}$.

O delineamento experimental foi em blocos casualizados, com oito tratamentos: adubação completa (testemunha), deficiente em nitrogênio $(-\mathrm{N})$, deficiente em fósforo (-P), deficiente em potássio $(-\mathrm{K})$, deficiente em cálcio $(-\mathrm{Ca})$, deficiente em magnésio $(-\mathrm{Mg})$, deficiente em enxofre $(-\mathrm{S})$ e deficiente em boro (-B), com quatro repetições. A unidade experimental foi composta por uma caixa com 46 litros de areia lavada e duas plantas por caixa.

Utilizou-se como material propagativo de sementes retiradas de frutos de maracujazeiro-doce adquiridos no comércio de Campos dos Goytacazes$\mathrm{RJ}$, cuja origem da produção era a região de Campinas-SP. As sementes foram tratadas para a quebra de dormência, utilizando-se de metodologias descritas por Martins et al. (2003), que consistem em escarificação com areia e imersão por 24 horas em ácido giberélico na concentração de $300 \mathrm{mg} \mathrm{L}^{-1}$. O plantio foi realizado em 30-09-2004, em bandejas de isopor, o substrato utilizado foi areia lavada, e o tempo de germinação foi, em média, 30 dias, após o plantio. As plântulas foram inicialmente irrigadas uma vez por dia com $5 \mathrm{~mL}$ célula ${ }^{-1}$ de solução completa $1 / 4 \mathrm{de}$ força $(25 \%$ da concentração de nutrientes sugerida na metodologia).

Quarenta e cinco dias após o plantio, seis plântulas foram transplantas por caixa, sendo estas preenchidas com areia lavada. No fundo da caixa, foi colocada uma camada com oito litros de areia com granulometria maior que $1,5 \mathrm{~mm}$ e sobre esta 38 litros com granulometria maior que $0,6 \mathrm{~mm}$, totalizando 46 litros de areia por caixa. Essas plântulas foram irrigadas por um período de 10 dias com solução nutritiva completa $1 / 2$ força $(50 \%$ da concentração de nutrientes) e depois com solução nutritiva com- 
pleta. Após 15 dias de transplantio, foi realizado um desbaste, deixando-se três plantas por caixa. Aos 64 dias após o plantio, eliminou-se uma planta por caixa, deixando-se, ao final, duas plantas mais uniformes. As plantas foram conduzidas em haste única até atingirem o arame superior da espaldeira, quando foram despontadas, realizando-se a condução de dois ramos laterais. Os ramos laterais foram podados quando atingiam $1,25 \mathrm{~m}$, para induzir o crescimento dos ramos terciários e, assim, formar uma cortina. $\mathrm{O}$ espaçamento utilizado foi de 2,0 m entre linhas e 2,5 $\mathrm{m}$ entre caixas na linha.

Aos 66 dias após o plantio, a solução completa foi reduzida, para $50 \%$ em todos os tratamentos. Nos tratamentos com deficiência induzida houve omissão total de N, P, K, Ca, Mg, S e B, a partir de 73 dias após o plantio. As soluções utilizadas no experimento encontram-se na Tabela 1, sendo que o $\mathrm{pH}$ delas foi sempre ajustado para 5,4. Durante todo o experimento, foram feitas observações e descrições dos sintomas nas folhas e frutos, até a manifestação máxima visível da deficiência do nutriente, que ocorreu com 85 dias nas folhas e 240 dias nos frutos, após o início da aplicação do tratamento. Como o objetivo do trabalho era avaliar os sintomas de deficiência também nos frutos, foi necessário aplicar soluções contendo o nutriente suprimido. Neste sentido, aplicou-se, no tratamento -N solução completa, por um período de 5 dias, aos 45; 75;100;125; 150 e 200 dias após a aplicação dos tratamentos. No tratamento -K solução completa por 5 dias aos 95 dias após aplicação do tratamento e no -Mg solução completa por um período de cinco dias aos 62 dias. Nos tratamentos $-\mathrm{Ca}$ e $-\mathrm{B}$, a solução completa foi colocada por um período de 30 dias, 62 dias após inicio da aplicação do tratamento - Ca e 75 e 100 dias para o deficiente em B. Para os tratamentos -P e-S, aplicou-se, por cinco dias, solução contendo $10 \%$ e $20 \%$ de cada nutriente específico, 75 dias após aplicação dos tratamentos.

Determinou-se, aos 250 dias após o início da aplicação dos tratamentos, a massa seca da parte aérea, das raízes e total por planta. Para determinar o teor dos nutrientes na massa seca foliar do maracujazeiro-doce, amostragens de folhas foram realizadas aos 30;60;90 e 240 dias após o início da aplicação dos tratamentos. Foram coletadas 10 folhas por parcela ( $4^{\mathrm{a}}$ folha totalmente expandida, sem pecíolo). As folhas foram acondicionadas em sacos de papel Kraft e secas em estufa com circulação forçada de ar à temperatura de $45^{\circ} \mathrm{C}$, durante 72 horas. O material foi então triturado em moinho (tipo Wiley) com peneira de 30 mesh e armazenado em frascos hermeticamente fechados. Os nutrientes analisados foram: nitrogênio $(\mathrm{N})$, fósforo $(\mathrm{P})$, potássio $(\mathrm{K})$, cálcio $(\mathrm{Ca})$, magnésio
$(\mathrm{Mg})$, enxofre (S) e boro (B). O N foi determinado pelo método de Nessler (JACKSON, 1965); o P, por colorimetria; o K, por fotometria de chama; $\mathrm{Ca}$ e $\mathrm{Mg}$ por espectrofotometria de absorção atômica; o $\mathrm{S}$, por turbidimetria com cloreto de bário, e o $\mathrm{B}$, pelo método da Azometina-H (JONES Jr. et al., 1991; MALAVOLTA et al., 1997).

Foi realizada análise de variância para massa seca da raiz, da parte aérea e total, e as médias foram comparadas com a testemunha (tratamento completo), pelo teste bilateral de Dunnet,a 5\% de probabilidade.

\section{RESULTADOS E DISCUSSÃO}

Os sintomas de deficiência de macronutrientes e de B nas plantas do maracujazeirodoce foram expressos nas folhas até 85 dias após o início da aplicação dos tratamentos e nos frutos até 240 dias (Figuras 1; 2; 3; 4; 5; 6 e 7).

As folhas mais velhas do ramo principal do maracujazeiro-doce, cultivado sob ausência de $\mathrm{N}$, foram as primeiras a apresentar sintomas de deficiência nutricional, o que ocorreu 16 dias após a aplicação da solução nutritiva sem nitrogênio; tais sintomas caracterizavam-se por clorose em todo o limbo foliar (Figura 1A), que progrediu para as folhas superiores e generalizou-se por toda a planta. As folhas velhas que estavam cloróticas tornaramse necrosadas e com queda prematura quando comparadas ao tratamento completo. Os sintomas verificados na folha do maracujazeiro-doce também foram citados por Fernandes et al.(1991) e Martinez e Araújo (2001) em espécies de Passiflora.

O teor de $\mathrm{N}$,aos 30 dias após o início da aplicação dos tratamentos, no tratamento sem $\mathrm{N}$, era $20,9 \mathrm{~g} \mathrm{~kg}^{-1}$, ou seja, $51,8 \%$ menor que o teor obtido no tratamento completo, que foi $43,4 \mathrm{~g} \mathrm{~kg}^{-1}$ (Tabela 2). A deficiência de $\mathrm{N}$ causou queda prematura dos frutos, a qual foi reduzida após a aplicação de solução completa por 10 dias. As flores apresentavam uma coloração desbotada (Figuras $1 \mathrm{C}_{1}$ e $1 \mathrm{C}_{2}$ ). Os frutos obtidos no tratamento sem $\mathrm{N}$ apresentavam-se com coloração amarelo- clara e aspecto translúcido (Figura 1D).

Geralmente, as descrições dos sintomas de deficiência de P são folhas verde-escuras, nas plantas cultivadas na ausência de $\mathrm{P}$, e os sintomas visuais de deficiência começaram a surgir após 62 dias da omissão deste nutriente. Caracterizado por coloração verde- escura brilhante (Figura 2A) nas quais,velhas que com o aumento da intensidade da deficiência, surgiam manchas claras no limbo (Figura 2B). Para 
maracujazeiro-doce, aos 70 dias após o plantio, Cereda et al. (1991) relataram, como sintoma de deficiência de $\mathrm{P}$, folhas com formato normal e limbo verde-escuro. Fernandes et al. (1991), avaliando por um período de 55 dias após o transplantio das mudas, concluíram que os sintomas de deficiência, de P não ficaram bem caracterizados no período avaliado. $\mathrm{O}$ tempo de avaliação dos sintomas de deficiência, na maioria dos trabalhos (NEVES et al., 2004; UTUMI et al., 1999; FERNANDES et al., 1991; CEREDA et al., 1991), durou entre 30 e 90 dias, ou seja, tempo muito curto para se caracterizar os sintomas de deficiência. Foi demonstrado no presente trabalho que, no início da deficiência, aparece um sintoma característico; entretanto, com a evolução da deficiência, os sintomas são modificados. Na época de aparecimento dos sintomas de deficiência de $\mathrm{P}$ nas folhas, o teor deste foi $66,4 \%$ menor que o teor encontrado no tratamento completo (Tabela 2). A deficiência de $P$ não afetou visualmente a aparência externa do fruto de maracujazeiro-doce.

Os sintomas de deficiência de $\mathrm{K}$ surgiram com 85 dias após a omissão desse nutriente, sendo caracterizados por clorose e posterior necrose na nervura central das folhas mais velhas (Figura $3 \mathrm{~A}, 3 \mathrm{~B}$ e $3 \mathrm{C}$ ), que progrediam para as bordas, provocando queda das folhas. Os ramos terciários eram menores e secavam (Figura 3D). Alguns autores, como Malavolta et al., (1997); Batista et al., (2003) e Taiz e Zeiger (2004), relataram, como sintoma de deficiência de potássio, clorose marginal avançando em direção à parte central das folhas mais velhas e depois necrose das margens e ponta das folhas. Cereda et al. (1991) relataram, como sintoma de deficiência de $\mathrm{K}$, folhas encarquilhadas, com necrose marginal e com pintas esbranquiçadas no limbo.

No início do aparecimento de sintomas de deficiência de $\mathrm{K}$ nas folhas, o teor deste nutriente foi $70,7 \%$ menor que o teor encontrado no tratamento completo (Tabela 2). Nos frutos de plantas cultivadas sob deficiência de $\mathrm{K}$, os sintomas de deficiência deste nutriente foram verificados aos 220 dias após o início da aplicação do tratamento e caracterizavamse por enrugamento do epicarpo com consequente murchamento do fruto (Figura $3 \mathrm{E}$ ).

Para o tratamento com omissão de $\mathrm{Ca}$, os sintomas de deficiência foram observados aos 22 dias após o início da aplicação do tratamento, e tais sintomas caracterizaram-se por encarquilhamento, deformação e necrose nas bordas das folhas novas (Figura 4A e 4B). A mobilidade muito baixa do cálcio na planta determina, segundo Taiz e Zeiger (2004), a expressão de sintomas da deficiência do cálcio em folhas novas. No início do aparecimento dos sintomas de deficiência de Ca nas folhas, o teor deste nutriente foi $75,8 \%$ menor que o teor encontrado no tratamento completo (Tabela 2).

$\mathrm{O}$ aumento da intensidade da deficiência de $\mathrm{Ca}$ no maracujazeiro-doce caracterizou-se por queda intensa de folhas, botões florais e flores e por seca dos ramos. Segundo Marschner (1995), a queda intensa de botões florais e de flores é uma das características de deficiência de Ca. As flores e os estigmas do maracujazeiro-doce, cultivadas na ausência de $\mathrm{Ca}$, apresentavam-se menores (Figura 4D) do que aquelas cultivadas sob solução completa (Figura 4C). Verificaram-se rachaduras intensas no epicarpo e no mesocarpo dos frutos (Figura 4E) e podridão apical dos frutos (Figura 4F).

Os primeiros sintomas de deficiência de $\mathrm{Mg}$ foram observados 36 dias após o início da aplicação do tratamento. As folhas velhas apresentaram clorose internerval, com uma faixa estreita de tecido verde ao longo das nervuras (Figura 5A), e com a progressão da deficiência as folhas tornaram-se amarelas, com parte das margens necrosada (Figura 5B) e queda intensa de folhas. Os sintomas verificados na folha do maracujazeiro-doce também foram citados por Malavolta et al. (1997), Batista et al. (2003) e Taiz e Zeiger (2004). Observa-se, na Tabela 2, que, no início do aparecimento dos sintomas de deficiência de $\mathrm{Mg}$ nas folhas, o teor deste nutriente foi $68,9 \%$ menor que o teor encontrado no tratamento completo. Verificouse, ainda, que as plantas cultivadas na omissão de $\mathrm{Mg}$ não floresceram mesmo com a aplicação a cada 40 dias de solução completa por 10 dias

Após 72 dias de omissão de S, apareceram os primeiros sintomas de deficiência desse nutriente em plantas do maracujazeiro-doce. Tais sintomas caracterizaram-se por redução no tamanho e clorose das folhas mais novas (Figura 6A), sendo que, nessas folhas, com a evolução da sintomatologia, apareceram pequenas manchas mais claras no limbo (Figura 6B). As folhas mais velhas do ramo permaneceram com um aspecto normal (Figura 6D). Na Figura 6C, verificam-se diferenças no tamanho e coloração da folha do tratamento completo com folha, menor e mais clorótica, do tratamento -S. Doze dias antes ao início do aparecimento de sintomas de deficiência de $\mathrm{S}$ nas folhas, o teor deste nutriente $\left(1,7 \mathrm{~g} \mathrm{~kg}^{-1}\right)$ foi $66,1 \%$ menor que o teor encontrado no tratamento completo $\left(4,9 \mathrm{~g} \mathrm{~kg}^{-1}\right)$.

O enxofre é considerado nutriente de mobilidade intermediária na planta, não sendo tão móvel quanto o N, P e K nem tão imóvel como Ca. Segundo Marschner (1995), em plantas supridas com quantidade adequada de $\mathrm{N}$, os sintomas de 
deficiência de $\mathrm{S}$ ocorrem primeiro nas folhas novas, e em plantas supridas com quantidades insuficientes de $\mathrm{N}$ os sintomas apareceram primeiro em folhas velhas, indicando que a redistribuição do $\mathrm{S}$ das folhas mais velhas para as mais novas dependem da senescência da folha a qual é induzida pelo estado nutricional de $\mathrm{N}$ na planta. Os sintomas de deficiência caracterizados para maracujazeiro-doce por Cereda et al. (1991) foram folhas com coloração verde-clara, semelhante à deficiência em $\mathrm{N}$, e bordos serrilhados, diferente daqueles observados no presente trabalho. A deficiência de $\mathrm{S}$ não afetou visualmente a aparência externa do fruto de maracujá-doce.

Os sintomas de deficiência de boro iniciaram-se 45 dias após a omissão desse nutriente. As folhas novas apresentaram aspecto coriáceo e ondulação nos bordos (Figura 7A), redução do comprimento dos internódios e paralisação do crescimento dos ramos, com necrose da gema apical e perda da dominância apical. Os sintomas verificados na folha do maracujazeiro-doce também foram relatados por Malavolta et al. (1997), Belvins e Lukaszewski (1998) e Taiz e Zeiger (2004).

Quinze dias antes do aparecimento dos primeiros sintomas de deficiência de B nas folhas, o teor deste nutriente $\left(12,8 \mathrm{~g} \mathrm{~kg}^{-1}\right)$ foi $80 \%$ menor que o teor encontrado no tratamento completo (64 $\mathrm{g} \mathrm{kg}^{-1}$ ) (Tabela 2). Segundo Belvins e Lukaszewski (1998) e Taiz e Zeiger (2004), em plantas com pouca mobilidade do boro, a deficiência resulta em necrose de tecidos meristemáticos na região de crescimento, conduzindo à perda da dominância apical. Verificouse, ainda, que, em plantas deficientes em B, ocorria seca de flores na planta (Figura 7C), além de flores deformadas com aparecimento de número anormal de estiletes, com estigmas maiores que aqueles observados nas flores do tratamento completo (Figura 7F). Belvins e Lukaszewski (1998) relatam que a deficiência de boro causa esterilização e deformações nas flores de monocotiledôneas e dicotiledôneas. Os frutos apresentaram, aos 235 dias após o início da aplicação do tratamento, deformações externas, como cortiça na casca (Figura 7D), que, segundo Malavolta et al. (1997), são sintomas de deficiência de B. Verificou-se, ainda, nas plantas deficientes em boro, redução no crescimento e engrossamento do ramo, além de superbrotações nas regiões apicais devido a perda da dominância apical (Figuras 7B, 7E e FG).

A produção de massa seca da raiz, da parte aérea e a massa seca total foram influenciadas pelos tratamentos (Tabela 3). Para a produção de raízes, os tratamentos deficientes em $\mathrm{S}$ e B não provocaram reduções na massa seca, quando comparados ao tratamento completo, e os decréscimos na produção de raízes foram da ordem de $43,6 \%$ para as plantas deficientes em $\mathrm{N}$ até $57,4 \%$ para as plantas deficientes em K (Tabela 3). Fernandes et al. (1991) observaram, no maracujazeiro-amarelo que, aos 55 dias após o transplantio, a produção de massa seca de raízes foi menor nos tratamentos deficientes em $\mathrm{N}, \mathrm{Mg}, \mathrm{P}$ e Ca.

A produção de massa seca da parte aérea do maracujazeiro-doce foi reduzida nos tratamentos com omissão de N, P e Ca (Tabela 3). Essas reduções variaram de $37,2 \%$ para plantas deficientes em $\mathrm{P}$ e $\mathrm{Ca}$ e de $46,5 \%$ para as plantas deficientes em N. Entretanto, não houve diferença significativa na massa seca da parte aérea dos tratamentos com omissão de S, Mg, B e K. Fernandes et al. (1991) observaram, para o maracujazeiro amarelo, cultivado em solução com omissão dos macronutrientes, que a produção de massa seca da parte aérea foi menor nos tratamentos com omissão de N, Mg e P. Taiz e Zeiger (2004) relatam que a deficiência de $\mathrm{S}$ reduz o crescimento das plantas, o que não foi verificado para o maracujazeiro-doce neste experimento. Provavelmente, as adições de soluções, contendo o nutriente em omissão, durante o período do experimento nos tratamentos deficientes em $\mathrm{S}, \mathrm{Mg}$, $\mathrm{B}$ e K, influenciaram nestas respostas. Esse manejo foi realizado para não ocorrer o colapso das plantas. Entretanto, observa-se, na Tabela 2, que os teores dos respectivos nutrientes foram menores do que no tratamento completo.

Em plantas cultivadas em solução sem $\mathrm{N}$, Ca e $\mathrm{P}$, a quantidade de massa seca total produzida foi menor em $46 ; 38$ e $38 \%$, respectivamente, quando comparadas ao tratamento completo (Tabela 3). Fernandes et al. (1991) observaram, para o maracujazeiro-amarelo cultivado até 55 dias após o transplantio, que a produção de massa seca total foi menor nos tratamentos com omissão de N, P e Mg. 
TABELA 1 - Composição das soluções nutritivas, completa e com omissão de N, P, K, Ca, Mg, S e B, utilizadas no experimento com maracujazeiro-doce.

\section{Solução}

Estoque

\begin{tabular}{lcccccccc}
\hline $\mathrm{Ca}_{\left(\mathrm{NO}_{3}\right)_{24} \mathrm{H}_{2} \mathrm{O}\left(2 \mathrm{~mol} \mathrm{~L}^{-1}\right)}$ & 1,5 & - & 1,5 & 1,5 & - & 1,5 & 1,5 & 1,5 \\
$\mathrm{KNO}_{3} \quad\left(2 \mathrm{~mol} \mathrm{~L}^{-1}\right)$ & 2,0 & - & 2,0 & - & 2,0 & 2,0 & 2,0 & 2,0 \\
$\mathrm{NH}_{4} \mathrm{H}_{2} \mathrm{PO}_{4}\left(1 \mathrm{~mol} \mathrm{~L}^{-1}\right)$ & 0,5 & - & - & 0,5 & 0,5 & 0,5 & 0,5 & 0,5 \\
$\mathrm{MgSO}_{4}\left(1 \mathrm{~mol} \mathrm{~L}^{-1}\right)$ & 2,0 & 2,0 & 2,0 & 2,0 & 2,0 & - & - & 2,0 \\
$\mathrm{FeEDTA}\left(25 \mathrm{~g} \mathrm{~L}^{-1}\right)$ & 1,0 & 1,0 & 1,0 & 1,0 & 1,0 & 1,0 & 1,0 & 1,0 \\
$\mathrm{MICRO}^{*}$ & 1,0 & 1,0 & 1,0 & 1,0 & 1,0 & 1,0 & 1,0 & 1,0 \\
$\mathrm{H}_{3} \mathrm{BO}_{3}(25 \mathrm{mM})$ & 1,0 & 1,0 & 1,0 & 1,0 & 1,0 & 1,0 & 1,0 & - \\
$\left(\mathrm{NH}_{4}\right)_{2} \mathrm{SO}_{4}\left(1 \mathrm{~mol} \mathrm{~L}^{-1}\right)$ & 0,5 & - & 0,5 & 0,5 & 0,5 & 0,5 & - & 0,5 \\
$\left.\mathrm{NH}_{4} \mathrm{Cl}_{(1 \mathrm{~mol} \mathrm{~L}}^{-1}\right)$ & - & - & 0,5 & - & - & - & 1,0 & - \\
$\mathrm{NaNO}_{3}\left(2 \mathrm{~mol} \mathrm{~L}^{-1}\right)$ & - & - & - & 2,0 & 3,0 & - & - & - \\
$\mathrm{Na}_{2} \mathrm{SO}_{4}\left(1 \mathrm{~mol} \mathrm{~L}^{-1}\right)$ & - & - & - & - & - & 2,0 & - & - \\
$\mathrm{MgCl}_{2} \quad\left(1 \mathrm{~mol} \mathrm{~L}^{-1}\right)$ & - & - & - & - & - & - & 2,0 & - \\
$\mathrm{CaCl}_{2}\left(2 \mathrm{~mol} \mathrm{~L}^{-1}\right)$ & - & 1,5 & - & - & - & - & - & - \\
$\mathrm{KCl}^{2}\left(1 \mathrm{~mol} \mathrm{~L}^{-1}\right)$ & - & 2,5 & - & - & - & - & - & - \\
$\mathrm{KH}_{2} \mathrm{PO}_{4}\left(1 \mathrm{~mol} \mathrm{~L}^{-1}\right)$ & - & 0,5 & - & - & - & - & - & - \\
$\mathrm{K}_{2} \mathrm{SO}_{4} \quad\left(0,5 \mathrm{~mol} \mathrm{~L}^{-1}\right)$ & - & 1,0 & - & - & - & - & - & - \\
\hline
\end{tabular}

*Micro: $\mathrm{CuSO}_{4} \mathrm{H}_{2} \mathrm{O}=250 \mathrm{mg} \mathrm{L}{ }^{-1}, \mathrm{KCl}=3728 \mathrm{mg} \mathrm{L}^{-1}, \mathrm{MnSO}_{4} \mathrm{H}_{2} \mathrm{O}=845 \mathrm{mg} \mathrm{L}^{-1}, \mathrm{ZnSO}_{{ }_{7}} \mathrm{H}_{2} \mathrm{O}=578 \mathrm{mg} \mathrm{L}^{-1},\left(\mathrm{NH}_{4}\right)_{6} \mathrm{Mo}_{7} \mathrm{O}_{24.4} \mathrm{H}_{2} \mathrm{O}$ $=88 \mathrm{mg} \mathrm{L}^{-1}$

\begin{tabular}{llllllll}
\multicolumn{8}{c}{ Tratamentos $\left(\mathrm{mL} \mathrm{L}^{-1}\right)$} \\
\hline Completo & $-\mathrm{N}$ & $-\mathrm{P}$ & $-\mathrm{K}$ & $-\mathrm{Ca}$ & $-\mathrm{Mg}$ & $-\mathrm{S}$ & $-\mathrm{B}$
\end{tabular}


TABELA 3 - Produção de massa seca da raiz, da parte área e da massa seca total de plantas de maracujazeirodoce, 326 dias após o plantio, cultivadas em solução ausente de macronutrientes e boro.

\begin{tabular}{lccc}
\hline \multirow{2}{*}{ Tratamento } & $\begin{array}{c}\text { Massa Seca da } \\
\text { Raiz }\end{array}$ & $\begin{array}{c}\text { Massa Seca da } \\
\text { Parte Aérea }\end{array}$ & $\begin{array}{c}\text { Massa Seca } \\
\text { Total }\end{array}$ \\
\cline { 2 - 4 } Completo & \multicolumn{3}{c}{ g planta $^{-1}$} \\
\hline$-\mathrm{N}$ & 101 & 1133 & 1234 \\
\hline$-\mathrm{P}$ & $57^{-}$ & $606^{-}$ & $663^{-}$ \\
$-\mathrm{K}$ & $54^{-}$ & $712^{-}$ & $766^{-}$ \\
$-\mathrm{Ca}$ & $43^{-}$ & $813^{\mathrm{ns}}$ & $856^{\mathrm{ns}}$ \\
$-\mathrm{Mg}$ & $48^{-}$ & $711^{-}$ & $759^{-}$ \\
$-\mathrm{S}$ & $44^{-}$ & $946^{\mathrm{ns}}$ & $990^{\mathrm{ns}}$ \\
$-\mathrm{B}$ & $96^{\mathrm{ns}}$ & $1008^{\mathrm{ns}}$ & $1104^{\mathrm{ns}}$ \\
\hline $\mathrm{CV}(\%)$ & $78^{\mathrm{ns}}$ & $850^{\mathrm{ns}}$ & $928^{\mathrm{ns}}$ \\
\hline
\end{tabular}

(') significativo e inferior ou $\left.{ }^{\left({ }^{n s}\right.}\right)$ não significativo em relação ao tratamento Completo, pelo teste de Dunnet, em nível de 5\% de probabilidade.
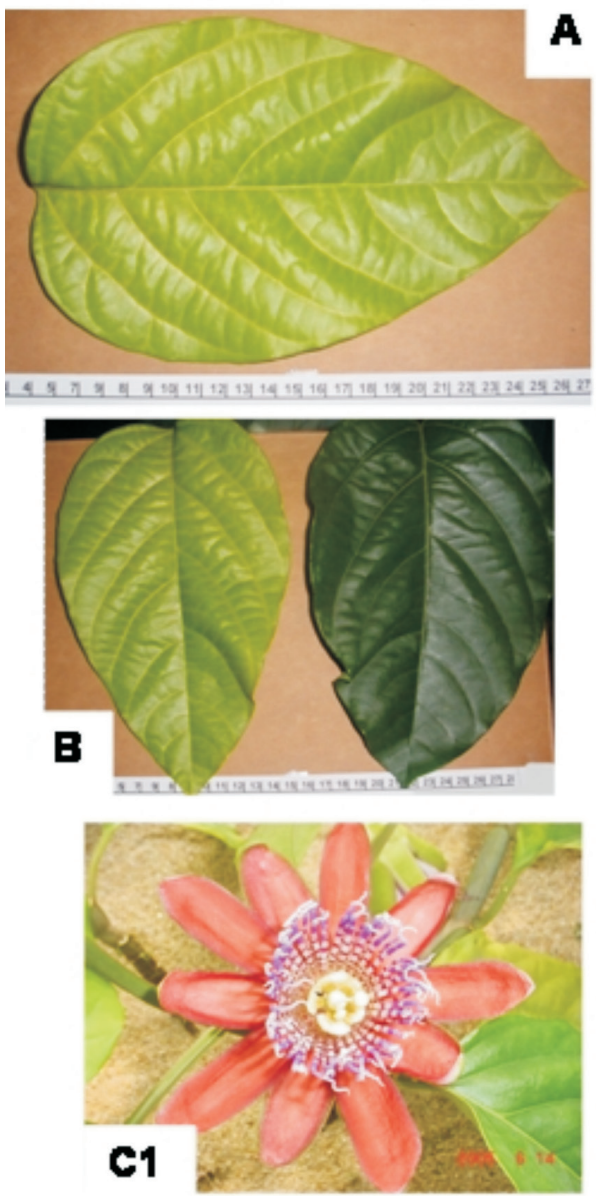
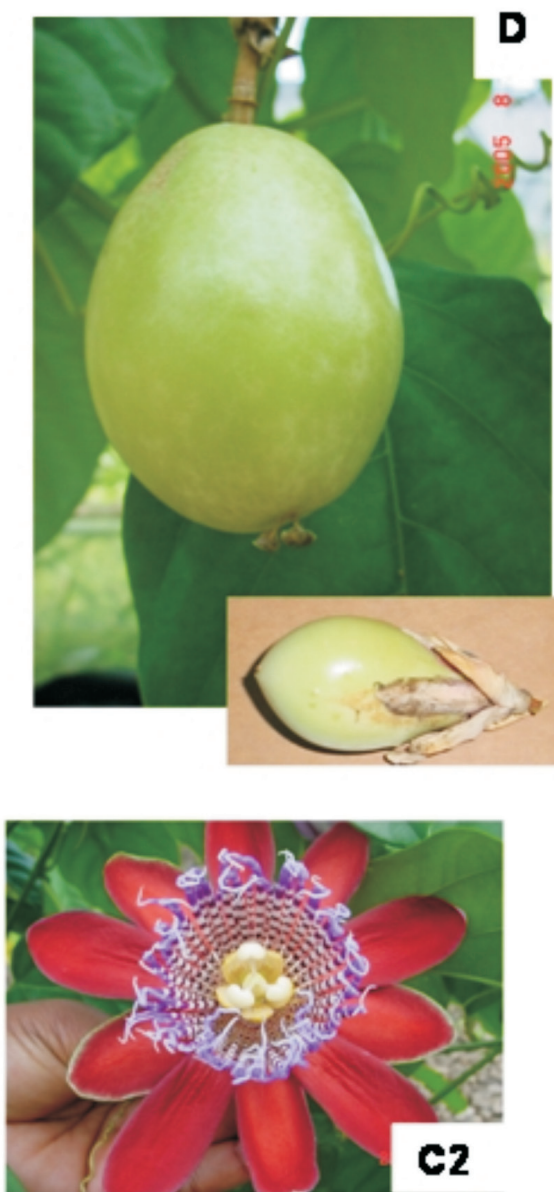

FIGURA 1 - Sintomas de deficiência de nitrogênio em maracujazeiro-doce. A: folha com clorose; B: comparação de folhas no tratamento completo (à direita) e sem N (à esquerda); C1: flor em plantas sem N; C2: flor em plantas no tratamento completo; D: fruto do tratamento sem $\mathrm{N}$ com aspecto translúcido. 

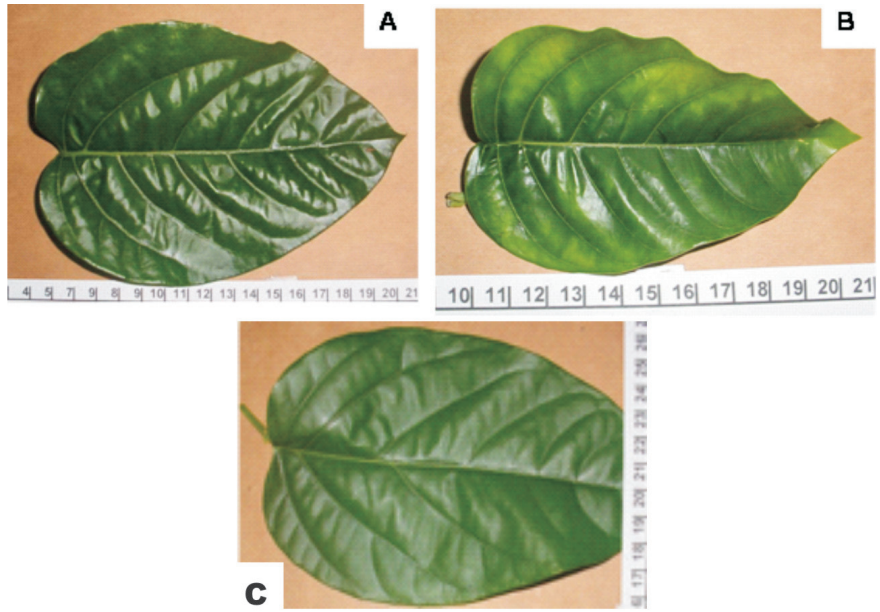

FIGURA 2- Sintomas de deficiência de fósforo em maracujazeiro doce: folhas com coloração verde escuro brilhante (A), com o aumento da intensidade da deficiência surgiam manchas claras pelo limbo (B) e folha de planta cultivada com tratamento completo (C).
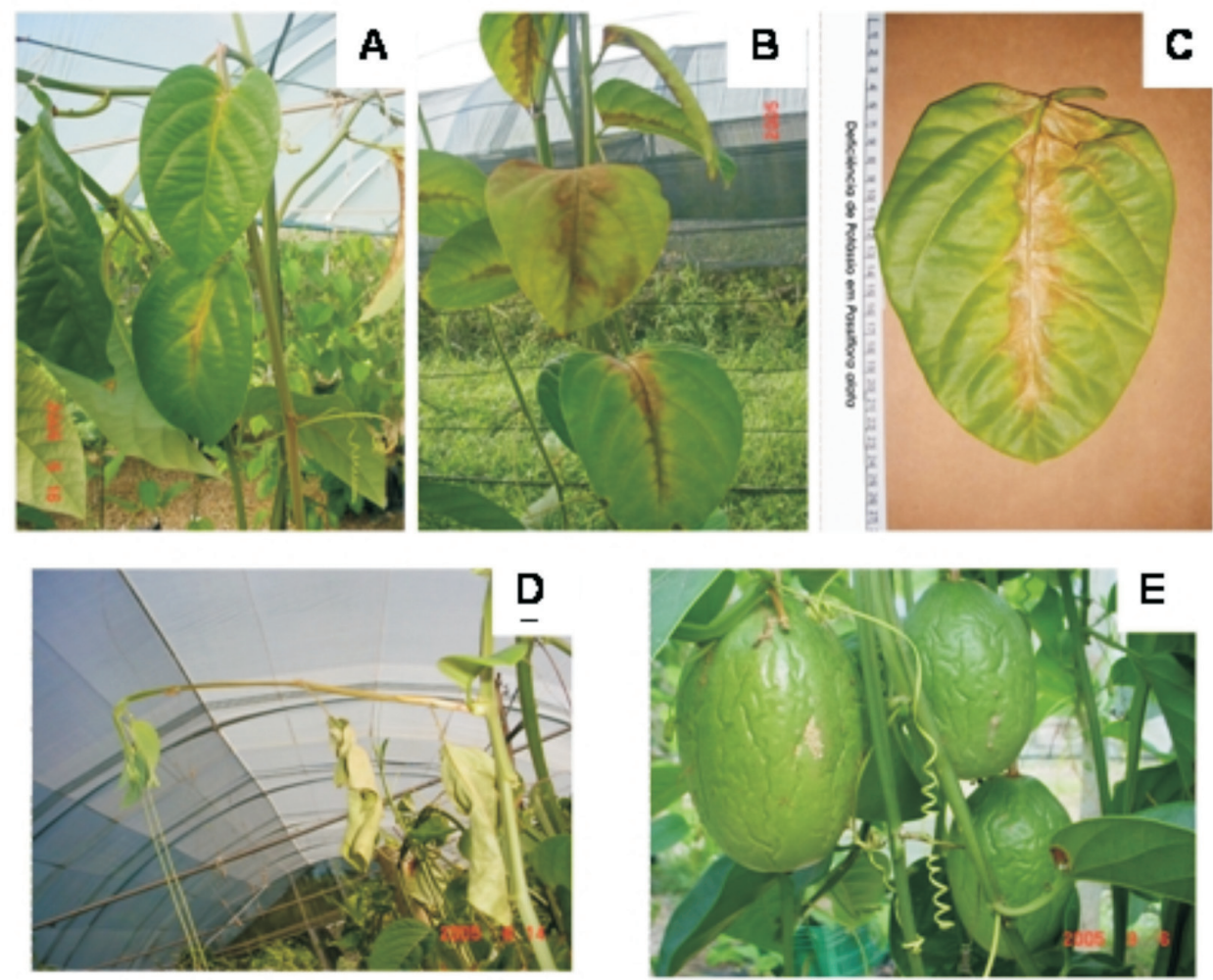

FIGURA 3 - Sintomas de deficiência de potássio em maracujazeiro-doce: folhas velhas com clorose e posterior necrose na nervura central das folhas que progrediam para as bordas, provocando queda das folhas (A, B e C), ramos terciários menores e secos (D) e frutos com enrugamento do pericarpo e murchos $(\mathrm{E})$. 

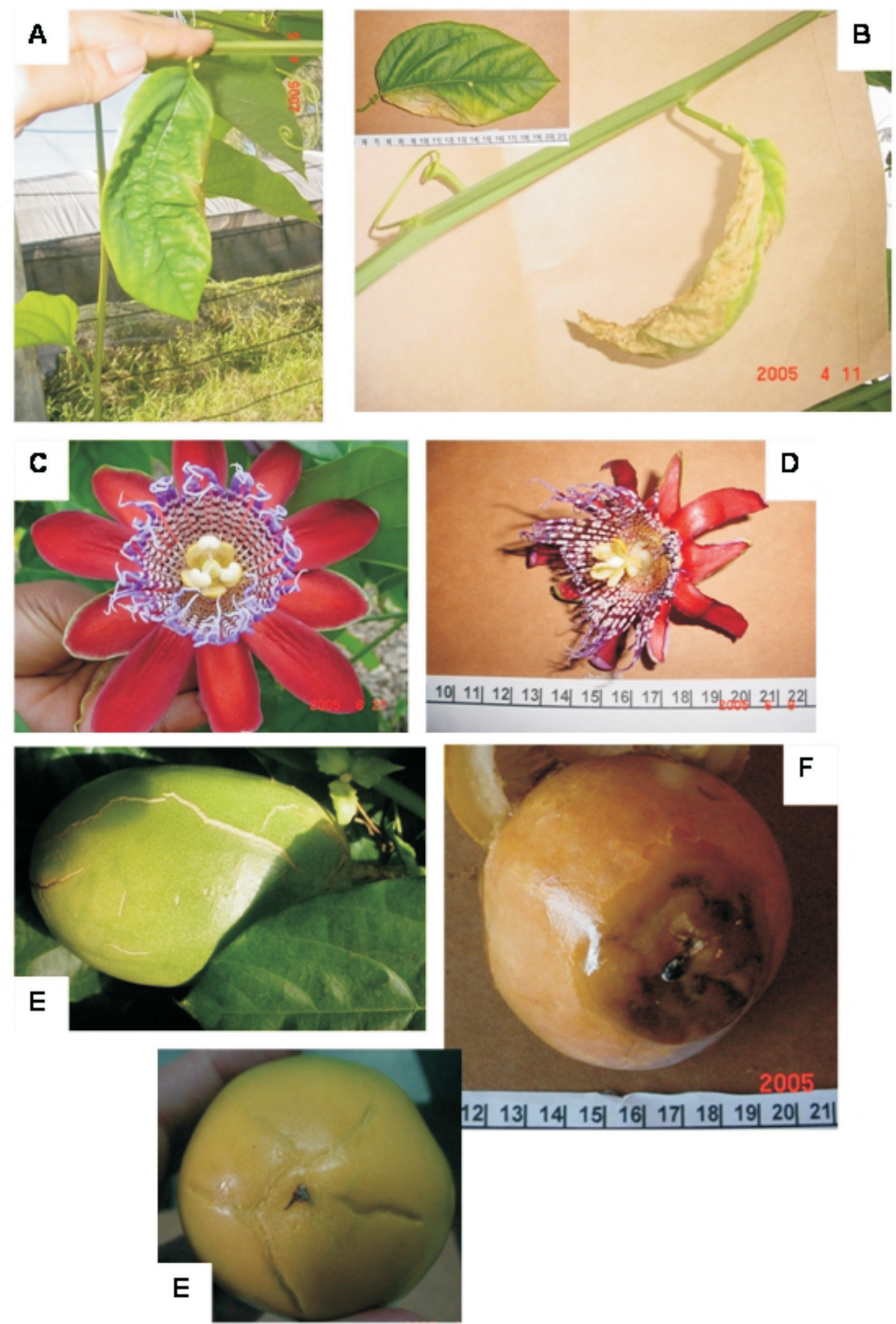

12| $13 \mid$\begin{tabular}{l|l|l|l|l|l|l|l|}
14 & 15 & 16 & 17 & 18 & 19 & $20 \mid$ & 21 \\
\hline
\end{tabular}

FIGURA 4 - Sintomas de deficiência de cálcio em maracujazeiro-doce: folhas novas deformadas com necrose nas bordas (A e B), flores e estigmas menores (D) em relação às flores do tratamento completo (C) e frutos do maracujazeiro-doce com rachaduras intensas no epicarpo e no mesocarpo dos frutos $(\mathrm{E})$ e podridão apical dos frutos $(\mathrm{F})$. 

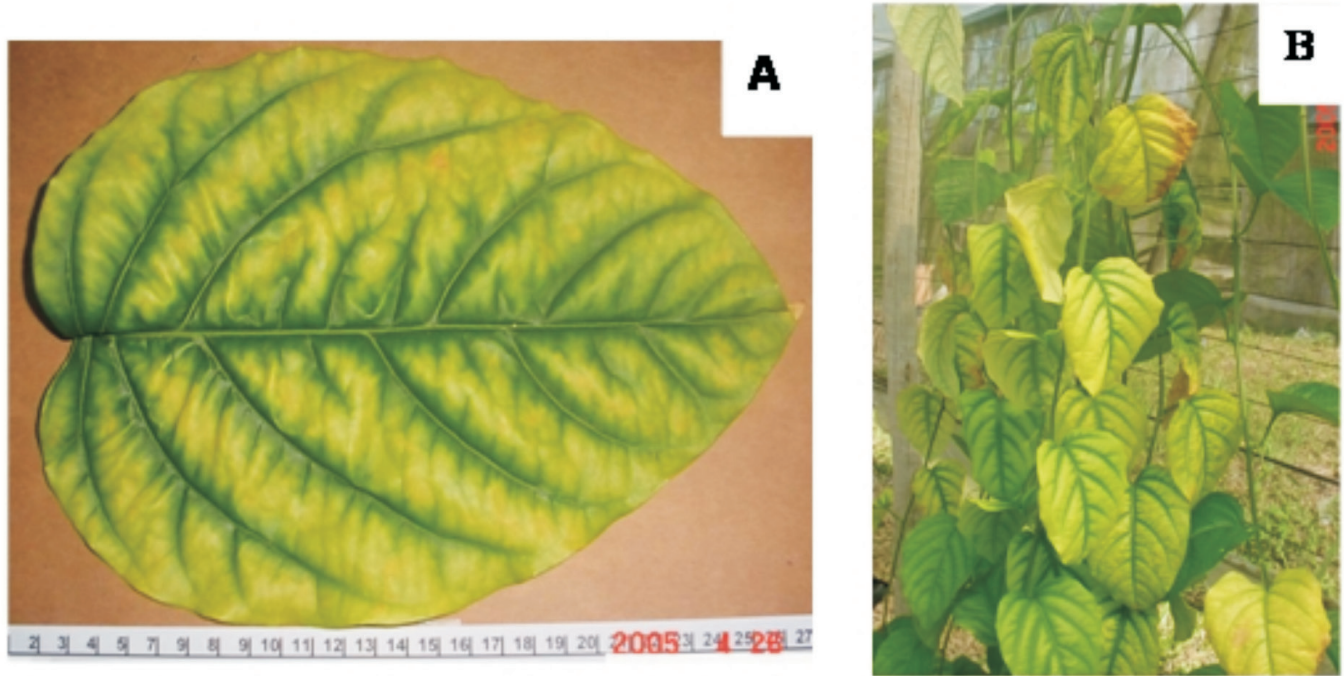

FIGURA 5 - Sintomas de deficiência de magnésio do maracujazeiro-doce: folhas velhas com clorose internerval (A) e com a progressão da deficiência, as folhas tornaram-se amarelas, com parte das margens necrosada (B).
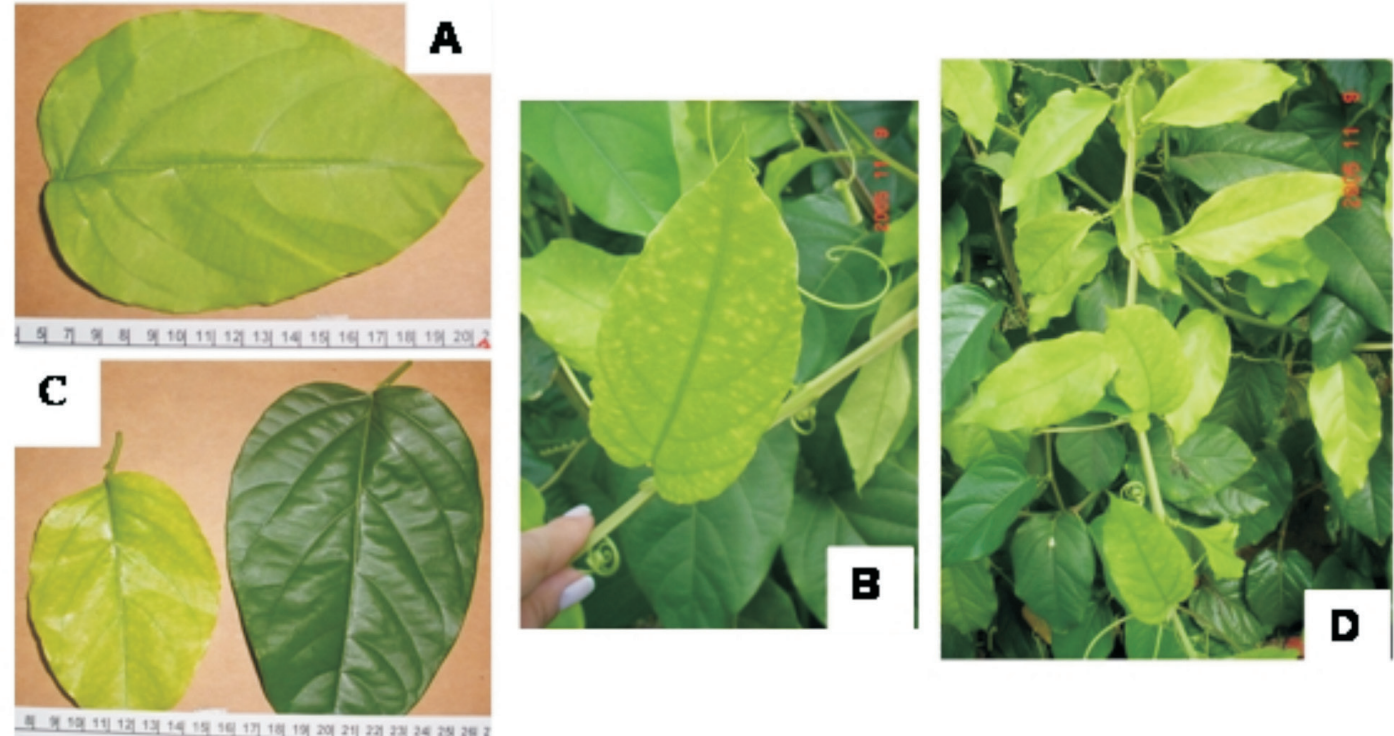

FIGURA 6 -Sintomas de deficiência de enxofre em folha de maracujazeiro-doce: folhas novas com tamanho reduzido e clorose (A). Com a evolução dos sintomas, surgiam nas folhas pequenas manchas mais claras no limbo (B). Comparação de uma folha do tratamento completo com tratamento sem S (C). As folhas mais velhas do ramo permaneceram com um aspecto normal (D). 

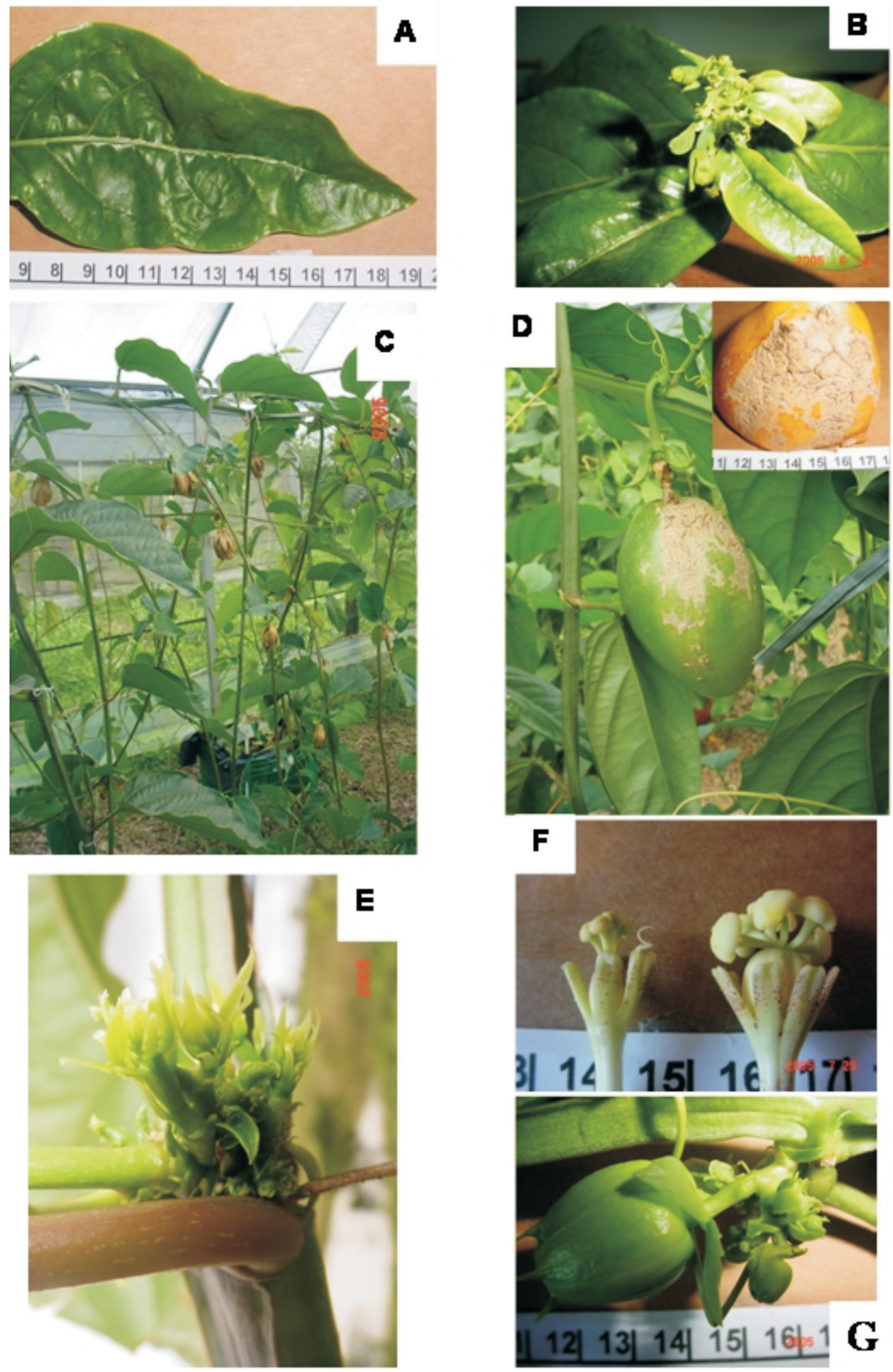

FIGURA 7 - Sintomas de deficiência de boro em maracujazeiro-doce: folha nova com aspecto coriáceo e ondulação nos bordos (A), flores secas na planta (C) e flores deformadas com maiores números de estiletes em relação ao tratamento completo (E). Frutos com cortiça na casca (D). Superbrotações nas regiões apicais da planta (B, E e G). 


\section{CONCLUSÕES}

1-Deficiência de N: clorose generalizada e queda prematura de folhas, flores com coloração vermelho-clara e frutos amarelo claros com aspecto translúcido.

2-Deficiência de P: folhas velhas com coloração verde-escura brilhante e, com a progressão da deficiência, surgiam manchas claras no limbo.

3-Deficiência de K: clorose e posterior necrose na nervura central de folhas velhas que progridem para as bordas e posterior queda. Frutos com enrugamento do epicarpo.

4-Deficiência de Ca: deformações e necrose nas bordas das folhas novas. Nos frutos, rachaduras no epicarpo e no mesocarpo, além de podridão apical.

5- Deficiência de $\mathrm{Mg}$ : folhas velhas com clorose internerval e não florescimento.

6- Deficiência de S: clorose das folhas mais novas com pequenas manchas mais claras.

7- Deficiência de B: folhas novas com aspecto coriáceo e ondulação nos bordos. Nos frutos deformações externas, como cortiça na casca.

8- A omissão de N, P e Ca são as que mais limitam a produção de raiz, parte aérea e massa seca total das plantas de maracujazeiro-doce.

\section{REFERÊNCIAS}

BATISTA, M.M.F.; VIÉGAS, I. de J.M.; FRAZÃO, D.A.C.; THOMAZ, M.A., SILVA, R. de C.L. de. Efeito da omissão de macronutrientes no crescimento, nos sintomas de deficiência nutricionais e na composição mineral de gravioleiras (Annona muricata). Revista Brasileira de Fruticultura, Jaboticabal, v.25, n.2, p.315-318, 2003.

BELVINS, D.G.; LUKASZEWSKI, K.M. Boron in plant structure and function. Annual Review Plant Physiology Plant Molecular Biology, Palo Alto v.49, p.481-500, 1998.
CEREDA, E.; ALMEIDA, I.M.L.; GRASSI FILHO, H. Distúrbios nutricionais em maracujá-doce (Passiflora alata Dryand) cultivado em solução nutritiva. Revista Brasileira de Fruticultura, Jaboticabal, v.13, n.4, p.241-244, 1991.

FERNANDES, D.M.; SILVA, J.C. da; GRASSI FILHO, H.; NAKOGAWA, J. Caracterização de sintomas de carência de macronutrientes em plantas de maracujá- amarelo (Passiflora edulis Sims f. flavicarpa) cultivado em solução nutritiva. Revista Brasileira de Fruticultura,Jaboticabal, v.13, n.4, p.233-240, 1991.

JACKSON, M.L.Soil chemical analysis. New Jersey: Prentice Hall, 1965. 498p.

JONES JR., J.B.;WOLF, B.; MILLS, H.A. Plant Analysis Handbook: a practical sampling, preparation, analysis, and interpretation guide. Athens: Micro-Macro Publishing, 1991. 213p.

MALAVOLTA, E.; VITTI, G.C.; OLIVEIRA, S.A. de. Avaliação do estado nutricional das plantas: princípios e aplicações. Piracicaba: POTAFÓS, 1997. 319p.

MARSCHNER, H. Mineral Nutrition of higher plants. $2^{\text {nd }}$ ed. San Diego: Academic Press, 1995. 889 p.

MARTINEZ, H.E.P.; ARAÚJO, R. da C.A. Nutrição e adubação. In: BRUCKNER, C.H.; PICANÇO, M.C. Maracujá: tecnologia de produção, póscolheita, agroindústria e mercado. Porto Alegre: Cinco Continentes, 2001. p.163-188.

MARTINS, M.R.; PEREIRA JÚNIOR, J.C.; GOMES, J.J.A.; RODRIGUES, R.C.M.; ARAÚJO, J.R.G. Avaliação de métodos de extração da mucilagem e de superação da dormência em sementes de maracujazeiro-doce (Passiflora alata Curtis). In: SIMPÓSIO BRASILEIRO SOBRE A CULTURA DO MARACUJAZEIRO, 6., 2003, Campos dos Goyatacazes. Anais... Campos dos Goyatacazes: UENF/UFRRJ, 2003. 4p.

NEVES, O.S.C.; SÁ, J. R; de CARVALHO, J.G. Crescimento e sintomas visuais de deficiência de micronutrientes em umbuzeiros. Revista Brasileira de Fruticultura, Jaboticabal, v.26, n.2, p.306-309, 2004. 
RAMOS, M.J.M; MONNERAT, P.H; CARVALHO, A. J.C de C; PINTO, J.L.A; SILVA, J.A.da. Sintomas visuais de deficiência de macronutrientes e de boro em abacaxizeiro 'imperial'. Revista Brasileira de Fruticultura, Jaboticabal, vol.31, n.1, p. 252-256, 2009.

TAIZ L. ZEIGER, E. Plant physiology. Redwood City: The Benjamin/Commings Publishing, 2004. 690 p.
UTUMI, M.M.; MONNERAT, P.H.; PEREIRA, P.R.G.; FONTES, P.C.R.; GODINHO, V. de P. C. Deficiência de macronutrientes em estévia: sintomas visuais e efeitos no crescimento, composição mineral e produção de esteviosídeo. Pesquisa Agropecuária Brasileira, Brasília, v.34, n.6, p.1039-1043, 1999.

VIÉGAS, I. de J.M.; THOMAZ, M.A.A.; SILVA, J.F. da; CONCEIÇÃO, H.E.O da; NAIFF, A.P.M. Efeito da omissão de macronutrientes e boro no crescimento, nos sintomas de deficiência nutricionais e na composição mineral de plantas de camucamuzeiro. Revista Brasileira de Fruticultura, Jaboticabal v.26, n.2, p.315-319, 2004. 